\title{
Removal of LAS from water by activated carbon and resins in continuous process
}

\author{
M. R. Franco Júnior ${ }^{1 *}$, N. R. A. F. Rocha ${ }^{2}$, W. A. Pereira ${ }^{2}$, N. P. Merlo ${ }^{2}$ \\ ${ }^{1}$ Post-Graduation Program in Biofuels, Chemistry Institute, Federal University of Uberlândia, Avenida João Naves de \\ Ávila, 2121 Santa Monica, 38408 100, Uberlândia MG Brazil \\ ${ }^{2}$ UniRV, Rio Verde University, Fazenda Fontes do Saber, Rio Verde, Goiás, Brazil
}

Received November 21, 2018; Revised February 27, 2019

\begin{abstract}
In this study, Purolite resins and activated carbon (AC) were used to remove LAS (linear dodecyl benzene sulfonate) from water. In some cases the conventional filtration at constant pressure released a negligible amount of residual surfactant $\left(<0.1 \mathrm{mg} \mathrm{L}^{-1}\right)$. Adsorption characteristics were investigated with anionic, cationic and mixed resins and activated carbon with different sizes. LAS adsorption onto the solid material was studied in a solution of low concentration $\left(0.50 \mathrm{mg} \mathrm{L}^{-1}\right)$. For comparison, some filters filled with resins and activated carbon were prepared, characterized and connected to the recipient bottom for filtration. The size of carbon particles really influenced the results, and the anionic resin exhibited better adsorption capacity than the others in this study. The ANOVA response surface analyses properly confirmed the experimental results.
\end{abstract}

Keywords: resins; activated carbon; filtration; continuous process; adsorption.

\section{INTRODUCTION}

Surfactants (surface active agents) are amphiphilic molecules containing two distinct parts: a hydrophilic group and a lipophilic group [1] and have negative impact both on the wastewater treatment process and more importantly on the environment. There are numerous papers published regarding the negative effect that surfactants had on the environment, wildlife and humans [2,3].

Palmer and Hatley [4] have published a critical review informing that numerous studies have shown that whilst activated sludge tanks can achieve removal efficiencies of between 98.9 and 99.9\% for LAS, a trickling filter has a much wider range of removal efficiencies between 89.1 and 99.1\% [5], whilst for alkylphenol ethoxylates the removal efficiency was more in the region of $90 \%$ [6].

The LAS removal can occur in several ways, such as precipitation, adsorption or degradation [7]. Berna et al. [8] considered that among these mechanisms biodegradation is of greater importance for the removal of chemical compounds present in aquatic environments. Scott and Jones [9] concluded that bacteria can use LAS as a source of carbon and energy or even co-metabolize it through biochemical microbial reactions [10]. Besides, recently, Motteran et al. [11] performed the characterization and identification of metabolic pathways of the microorganisms involved in the degradation of the linear alkylbenzene sulfonate in comercial laundry wastewater in an enlarged scale fluidized bed reactor.

Ten years ago, Yoona and co-workers [12] investigated the mechanisms of perchlorate adsorption on activated carbon (AC) and anion exchange resin (SR-7 resin) using Raman, FTIR, and zeta potential analyses. Batch adsorption and desorption results demonstrated that the adsorption of perchlorate by AC and SR-7 resin was reversible. The reversibility of perchlorate adsorption by the resin was also proved by column regeneration test.

In recent years, Yu et al., 2009 [13] trying to adsorb perfluorooctane sulfonate (PFOS) and perfluorooctanoate (PFOA) on powdered activated carbon (PAC), granular activated carbon (GAC) and anion-exchange resin (AI400) to remove PFOS and PFOA from water, have realized that time of filtration was really important for the adsorbent choice. Sorption kinetic results showed that the adsorbent size influenced greatly the sorption velocity, and both the GAC and AI400 required over $168 \mathrm{~h}$ to achieve the equilibrium, much longer than the $4 \mathrm{~h}$ needed for the PAC.

The objectives of this study are to investigate the sorption behavior of LAS on the commercial adsorbents including activated carbon with four sizes and resins (anionic, cationic and mixed), and evaluate their sorption in terms of turbidity and conductivity at ambient temperatures with no $\mathrm{pH}$ correction. The possible influences of carbon size and type of resins among the adsorbents and adsorbate were also discussed.

\section{EXPERIMENTAL}

The equipment is shown in Fig. 1. The fixed bed filter was built in the Laboratório de Bromatologia from University of Rio Verde - UniRV. Experiments were performed using filters filled with activated carbon and resins to evaluate LAS

\footnotetext{
* To whom all correspondence should be sent. (C) 2019 Bulgarian Academy of Sciences, Union of Chemists in Bulgaria 
M. R. Franco Júnior et al.: Removal of LAS from water by activated carbon and resins in a continuous process. adsorption from residual water. The resins used were purchased from Purolite (anionic, cationic and mixed) and the activated carbon from Vetec. The activated carbon (AC) was prepared by using sieves to obtain four different sizes: $48,60,100$ and 300 mesh. The solid material was packed into a glass column and weighed on an analytical balance. Filters (4) were connected in the bottom of the tank

(1). The filtration tests were conducted by passing LAS solutions through the resin or AC column at the same drop pressure. The effluent samples or filtrates were collected at different times for analysis. All effluent samples were collected into a container for measurement of conductivity, turbidity and LAS concentration.

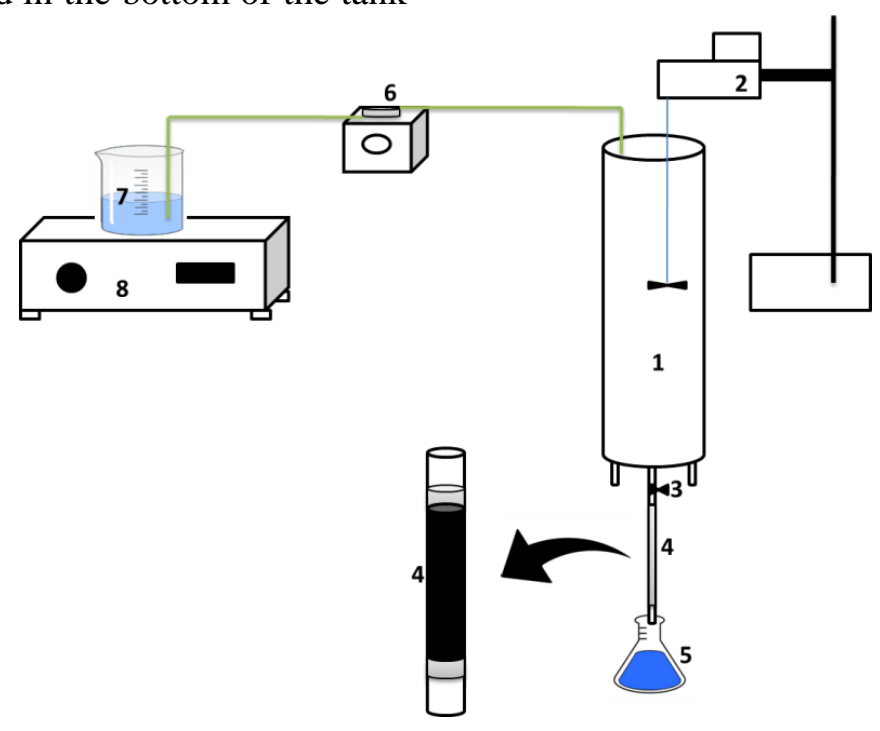

Fig. 1. Schematic view of the equipment used in this work ( 1 - tank, 2 - agitator engine, 3 - valve, 4 - filter, 5 - filtrate, 6 - metering pump, 7 - LAS solution or residual water, 8 - magnetic stirrer).

The contaminated water was put in the tank that was made of PVC cylindrical tube (1), with internal diameter of $0.08 \mathrm{~m}$. The residual water inside was stirred using a mechanical agitator (2) (IKA Model RW 20 D S1), with rotation frequency of $350 \mathrm{rpm}$. There were three outing tubes or fixed bed filters, with internal diameter of $0.007 \mathrm{~m}$, made of glass connected in the base of the PVC tube. They were filled with the adsorbent material for extracting LAS from the liquid. Also, all link tubes were made of flexible Teflon and had $0.0008 \mathrm{~m}$ internal diameter. All experiments were carried out at ambient temperature which varied around $(25 \pm 1)$ ${ }^{\circ} \mathrm{C}$. To maintain constant pressure and LAS concentration $\left(\mathrm{C}_{0}=0.50 \mathrm{mg} \mathrm{L}^{-1}\right)$ fed to the filters, the metering bomb (BIOTEC- Model FCE 0505 FP) (6) was used to constantly feed stirred (Tecnal modelo TE-0852 - $10 \mathrm{rpm}$ ) solution from tank (7) to tank (1).

\section{Materials and methods}

All chemicals were obtained from Vetec and Reagan In. Químicas, Brazil, including LAS linear dodecyl benzene sulfonate. All chemicals were of A.R. grade and used without further purification. Ultrapure water was used throughout the study to prepare aqueous solutions. Resins were acquired from Purolite Company Ltd.
The activated carbon (AC) used as adsorbent had the following sizes (mesh): 48, 60, 100 and 300. In addition, three types of resins were employed as follows: anionic, cationic and mixed. Table 1 shows the material, amount $(\mathrm{m})$ and length (h) of each filter used.

Table 1. Description of the filters connected in the base of the fixed reactor.

\begin{tabular}{c|c|c|c}
\hline Filter & Material & $\mathrm{m}(\mathrm{g})$ & $\mathrm{h}(\mathrm{cm})$ \\
\hline F1 & AC 48 & 1.2820 & 10 \\
\hline F2 & AC 60 & 1.2631 & 10 \\
\hline F3 & AC 100 & 1.3774 & 10 \\
\hline F4 & AC 300 & 1.3976 & 10 \\
\hline F5 & AR & 1.3494 & 10 \\
\hline F6 & CR & 2.3367 & 10 \\
\hline F7 & MR & 2.0792 & 10 \\
\hline
\end{tabular}

Legend: F- filter, AC - activated carbon (size), AR anionic resin, CR - cationic resin, MR - mixed resin.

For turbidity measurements, the turbidity meter model AP 2000 from Poli Control $( \pm 0.01$ NTU or \pm 0.1 NTU) was employed. The filtrate conductivities were determined on a conductivity meter model CD 850 in $\mu \mathrm{S}$ (micro Siemens/cm). The concentration of surfactant was determined indirectly using a spectrophotometer (UV-VIS) 
M. R. Franco Júnior et al.: Removal of LAS from water by activated carbon and resins in a continuous process.

TECNAL- Model SP-1105 at a wavelength of 650 $\mathrm{nm}$.

\section{RESULTS AND DISCUSSION}

Surfactant concentration, filtrate turbidity and conductivity in aqueous phase are shown in tables 2-4 when activated carbon was used as filter filling. Turbidity and conductivity of filtrate significantly decreased with the time of filtration, especially for meshs 48-100. For mesh 300 it was observed that the small particles of carbon undetermined the result. It clearly indicated that filtration has better removal efficiency $(88 \%)$ after $6 \mathrm{~h}$ of filtering and the filter with mesh 300 can be distinguished among the others.

Table 2. LAS concentration in the filtrate as a function of time for all $\mathrm{AC}$ meshs at the exit of the fixed bed. $\left(\mathrm{C}_{0}=0.50 \mathrm{mg} \mathrm{L}^{-1}\right)$

\begin{tabular}{c|c|c|c|c|c|c|c|c}
\hline \multirow{2}{*}{ Mesh } & \multicolumn{10}{|c}{ Filtration Time } \\
\cline { 2 - 10 } & $1 \mathrm{~h}$ & $2 \mathrm{~h}$ & $3 \mathrm{~h}$ & $4 \mathrm{~h}$ & $5 \mathrm{~h}$ & $6 \mathrm{~h}$ & $7 \mathrm{~h}$ & $8 \mathrm{~h}$ \\
\hline 48 & 0.263136 & 0.249124 & 0.201485 & 0.152445 & 0.153846 & 0.117416 & 0.180468 & 0.24352 \\
\hline 60 & 0.249124 & 0.2197 & 0.194479 & 0.166456 & 0.152445 & 0.166456 & 0.187474 & 0.214096 \\
\hline 100 & 0.298164 & 0.230909 & 0.190276 & 0.120219 & 0.15805 & 0.062771 & 0.075382 & 0.117416 \\
\hline 300 & 0.335996 & 0.221101 & 0.148242 & 0.156648 & 0.089393 & 0.059969 & 0.075382 & 0.106207 \\
\hline
\end{tabular}

Table 3. Turbidity of the filtrate as a function of time for all AC meshs at the exit of the fixed bed.

\begin{tabular}{c|c|c|c|c|c|c|c|c}
\hline \multirow{2}{*}{ Mesh } & \multicolumn{9}{|c}{ Filtration Time } \\
\cline { 2 - 10 } & $1 \mathrm{~h}$ & $2 \mathrm{~h}$ & $3 \mathrm{~h}$ & $4 \mathrm{~h}$ & $5 \mathrm{~h}$ & $6 \mathrm{~h}$ & $7 \mathrm{~h}$ & $8 \mathrm{~h}$ \\
\hline 48 & 0.36 & 0.14 & 0.02 & 0.15 & 0.02 & 0.29 & 0.02 & 0.22 \\
\hline 60 & 0.45 & 0.16 & 0.4 & 0.02 & 0.02 & 0.02 & 0.12 & 0.16 \\
\hline 100 & 0.41 & 0.33 & 0.2 & 0.02 & 0.23 & 0.26 & 0.31 & 0.06 \\
\hline 300 & 0.69 & 0.52 & 0.44 & 0.35 & 0.31 & 0.47 & 0.41 & 0.35 \\
\hline
\end{tabular}

Table 4. Conductivity of the filtrate as a function of time for all AC meshs at the exit of the fixed bed.

\begin{tabular}{c|c|c|c|c|c|c|c|c}
\hline \multirow{2}{*}{ Mesh } & \multicolumn{9}{|c}{ Filtration Time } \\
\cline { 2 - 10 } & $1 \mathrm{~h}$ & $2 \mathrm{~h}$ & $3 \mathrm{~h}$ & $4 \mathrm{~h}$ & $5 \mathrm{~h}$ & $6 \mathrm{~h}$ & $7 \mathrm{~h}$ & $8 \mathrm{~h}$ \\
\hline 48 & 18.6 & 7.5 & 6.1 & 4.5 & 3.9 & 3.5 & 3.1 & 2.9 \\
\hline 60 & 36.6 & 13.2 & 8.4 & 5.8 & 5 & 4.4 & 4.4 & 3.2 \\
\hline 100 & 5.2 & 4.5 & 4.3 & 4.3 & 5.1 & 4.1 & 4.1 & 3.9 \\
\hline 300 & 17.1 & 15.5 & 14 & 13.7 & 13.7 & 12.4 & 12.2 & 11.1 \\
\hline
\end{tabular}

Table 5. LAS concentration (mg. $\mathrm{L}^{-1}$ ) of the filtrate as a function of time for all resins at the exit of the fixed bed.

\begin{tabular}{c|c|c|c|c|c|c|c|c}
\hline \multirow{2}{*}{ Resin } & \multicolumn{9}{|c}{ Filtration Time } \\
\cline { 2 - 10 } & $1 \mathrm{~h}$ & $2 \mathrm{~h}$ & $3 \mathrm{~h}$ & $4 \mathrm{~h}$ & $5 \mathrm{~h}$ & $6 \mathrm{~h}$ & $7 \mathrm{~h}$ & $8 \mathrm{~h}$ \\
\hline ANI & 0.1265 & 0.141 & 0.08 & 0.064 & 0.1195 & 0.156 & 0.1205 & 0.139 \\
\hline CAT & 0.213 & 0.226 & 0.331 & 0.263 & 0.206 & 0.296 & 0.299 & 0.262 \\
\hline MIX & 0.107 & 0.103 & 0.064 & 0.082 & 0.116 & 0.072 & 0.085 & 0.089 \\
\hline
\end{tabular}


M. R. Franco Júnior et al.: Removal of LAS from water by activated carbon and resins in a continuous process.

Table 6. Turbidity (NTU) of the filtrate as a function of time for all resins at the exit of the fixed bed.

\begin{tabular}{c|c|c|c|c|c|c|c|c}
\hline \multirow{2}{*}{ Resin } & \multicolumn{8}{|c}{ Filtration Time } \\
\cline { 2 - 10 } & $1 \mathrm{~h}$ & $2 \mathrm{~h}$ & $3 \mathrm{~h}$ & $4 \mathrm{~h}$ & $5 \mathrm{~h}$ & $6 \mathrm{~h}$ & $7 \mathrm{~h}$ & $8 \mathrm{~h}$ \\
\hline ANI & 0.211994 & 0.23231 & 0.14684 & 0.124422 & 0.202186 & 0.253328 & 0.203587 & 0.229508 \\
\hline CAT & 0.333193 & 0.351408 & 0.498529 & 0.403251 & 0.323385 & 0.449489 & 0.453692 & 0.40185 \\
\hline MIX & 0.184671 & 0.179067 & 0.124422 & 0.149643 & 0.197282 & 0.135631 & 0.153846 & 0.159451 \\
\hline
\end{tabular}

Table 7. Conductivity $\left(\mu \mathrm{S} \mathrm{cm}^{-1}\right)$ of the filtrate as a function of time for all resins at the exit of the fixed bed.

\begin{tabular}{c|c|c|c|c|c|c|c|c}
\hline \multirow{2}{*}{ Resin } & \multicolumn{9}{|c}{ Filtration Time } & \multicolumn{1}{c}{} \\
\cline { 2 - 11 } & $1 \mathrm{~h}$ & $2 \mathrm{~h}$ & $3 \mathrm{~h}$ & $4 \mathrm{~h}$ & $5 \mathrm{~h}$ & $6 \mathrm{~h}$ & $7 \mathrm{~h}$ & $8 \mathrm{~h}$ \\
\hline ANI & 5.8 & 3.4 & 3.75 & 3.9 & 3.85 & 3.4 & 3.9 & 3.75 \\
\hline CAT & 14.9 & 6.3 & 7.3 & 7.1 & 7.1 & 3.3 & 4 & 4.4 \\
\hline MIX & 14 & 0.8 & 0.7 & 0.8 & 0.8 & 1.3 & 0.8 & 0.7 \\
\hline
\end{tabular}

Table 8. The ANOVA results of the regression model for filtrate LAS concentration (mg/L).

\begin{tabular}{c|lcccc} 
Parameter & \multicolumn{1}{|c}{ SQ } & GL & MQ & $\mathrm{F}_{0} \mathrm{C}$ & $\mathrm{F}_{0} \mathrm{~T}$ \\
\hline A & 0.267688627 & 2 & 0.133844313 & 47.74252 & 3.74 \\
B & 0.00629324 & 7 & 0.000899034 & 0.320687 & 2.76 \\
AB & 0.039248457 & 14 & 0.002803461 & & \\
TOTAL & 0.313230323 & & & & \\
\hline
\end{tabular}

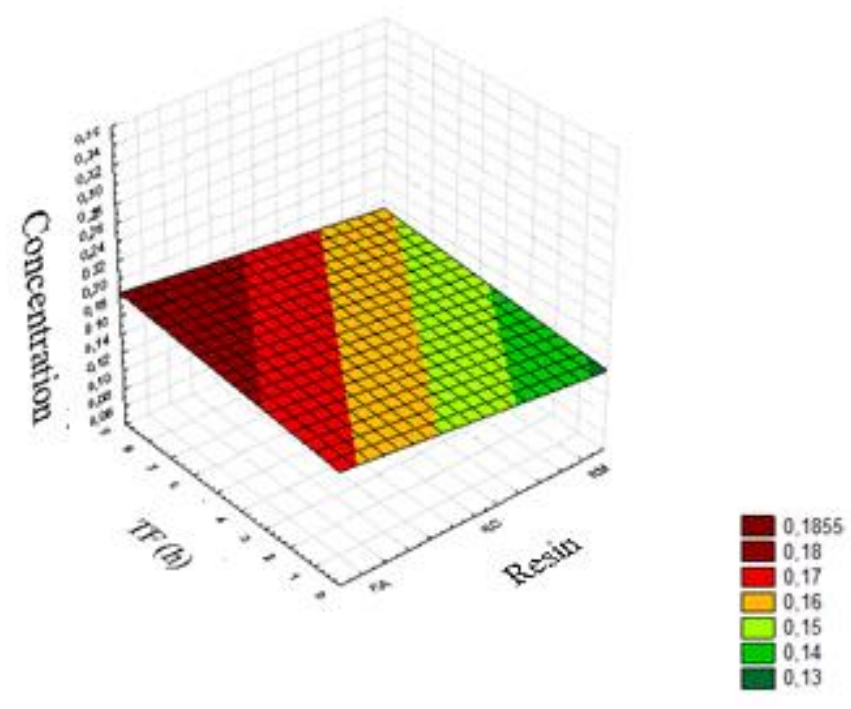

Fig. 2. Response surface for the effect of type of resin and filtration time (FT) on the filtrate LAS concentration (mg/L).

Tables 5-7 show the results of LAS concentration, turbidity and conductivity of filtrate for filters filled with resins. For all resins, turbidity does not change in the filtrate as time of filtration reached $8 \mathrm{~h}$. It seems that the anionic resin was the best one to remove LAS $(87.2 \%)$ from the aqueous solutions. This result is distinguished when compared to other adsorbents published by Nie et al. [14] that attribute the range of $30-70 \%$ to LAS removal efficiency. A better discussion will be done using response surfaces as follows.
The ANOVA results for the fixed effect model are shown in tables 8-10. In all tables A, B, AB are significant model terms that affect the parameter analysed. Also, in these tables each variable means: SQ (sum of squares), DF (degree of freedom), MQ (mean square), $\mathrm{F}_{0} \mathrm{C}$ (F-value) and $\mathrm{F}_{0} \mathrm{~T}$ (P-value). Pvalue (or $\mathrm{F}_{0} \mathrm{~T}$ ) is the tool to check the significance of each term. The term is more significant with a lower P-value and higher (or $\mathrm{F}_{0} \mathrm{C}$ ) F-value. Values of Prob $>\mathrm{F}<0.0500$ indicate that model terms are significant. 
M. R. Franco Júnior et al.: Removal of LAS from water by activated carbon and resins in a continuous process.

The response surfaces were generated by Design Expert after model fitting, as shown in Figs. 2-4. The influences of each factor (A: type of resin, B: filtration time) and their interactions $(\mathrm{AB})$ on the each variable could be analyzed according to the response surfaces.

Table 8 presents the analysis of variance to verify the effects of A and B on the LAS filtrate concentration. It can be seen that the high F-value of 47.74 and low P-value of 2.76 implied that the type of resin was highly significant. Between the two variables, the type of resin was the more significant one that affected the filtrate concentration according to the statistical analysis.

Fig. 2 confirms that the concentration is clearly affected by the type of resin (A) and is not so affected by the time of filtration (B) when the pressure drop is fixed at level $0(0.45 \mathrm{~m}$ water column). With the increase in filtration time, LAS concentration generally decreased for the anionic resin and kept the same for the others. Table 9 illustrates the analysis of variance to verify the effects of A and B in the filtrate turbidity. It can be seen that the small F-value of around 2.00 and relatively high P-value of 3.74 implied that the type of resin and time of filtration had similar significance in the results. Between the two variables, the type of resin was the more significant one that affected the filtrate concentration according to the statistical analysis.

Fig. 3 confirms that apart from the anionic resin in the four initial times the turbidity is not clearly affected by the type of resin (A) and is not affected by the time of filtration (B) when the pressure drop is fixed ( $0.45 \mathrm{~m}$ water column). With the increase in filtration time, turbidity was maintained the same for all tested resins. This was consistent with the ANOVA results in Table 9 that the F-values for A and $\mathrm{B}$ were similar to their $\mathrm{P}$-values.

Table 10 illustrates the analysis of variance to verify the effects of $\mathrm{A}$ and $\mathrm{B}$ on the filtrate conductivity. It can be seen that the reasonable Fvalue of around 8.00 and the relatively high $\mathrm{P}$-value of 3.74 implied that the type of resin had more significance than time of filtration on the results. Between the two variables, the type of resin was the more significant one that affected the filtrate conductivity according to the statistical analysis. In addition, the small values of conductivity at the end of the filtration mean low LAS concentration.

Fig. 4 confirms that the anionic resin had particularly good performance in LAS adsorption, followed by the mixed resin.

Table 9. The ANOVA results of the regression model for filtrate turbidity.

\begin{tabular}{cccccc}
\hline Parameter & SQ & GL & MQ & $\mathrm{F}_{0} \mathrm{C}$ & $\mathrm{F}_{0} \mathrm{~T}$ \\
\hline $\mathrm{A}$ & 0.033475 & 2 & 0.016738 & 1.98763 & 3.74 \\
$\mathrm{~B}$ & 0.123083 & 7 & 0.017583 & 2.088075 & 2.76 \\
$\mathrm{AB}$ & 0.117892 & 14 & 0.008421 & & \\
TOTAL & 0.27445 & & & \\
\hline
\end{tabular}

$\mathrm{A}=\operatorname{Resin}($ anionic (1), cationic (2) and mixed (3)); $\mathrm{B}=$ filtration time (1 to $8 \mathrm{~h}$ ).

Table 10. The ANOVA results of the regression model for filtrate conductivity.

\begin{tabular}{cccccc}
\hline Parameter & SQ & GL & MQ & F C & $\mathrm{F}_{0} \mathrm{~T}$ \\
\hline A & 76.82062 & 2 & 38.41031 & 7.983413 & 3.74 \\
B & 180.6307 & 7 & 25.80439 & 5.363328 & 2.76 \\
AB & 67.35771 & 14 & 4.811265 & & \\
TOTAL & 324.8091 & & & & \\
\hline
\end{tabular}




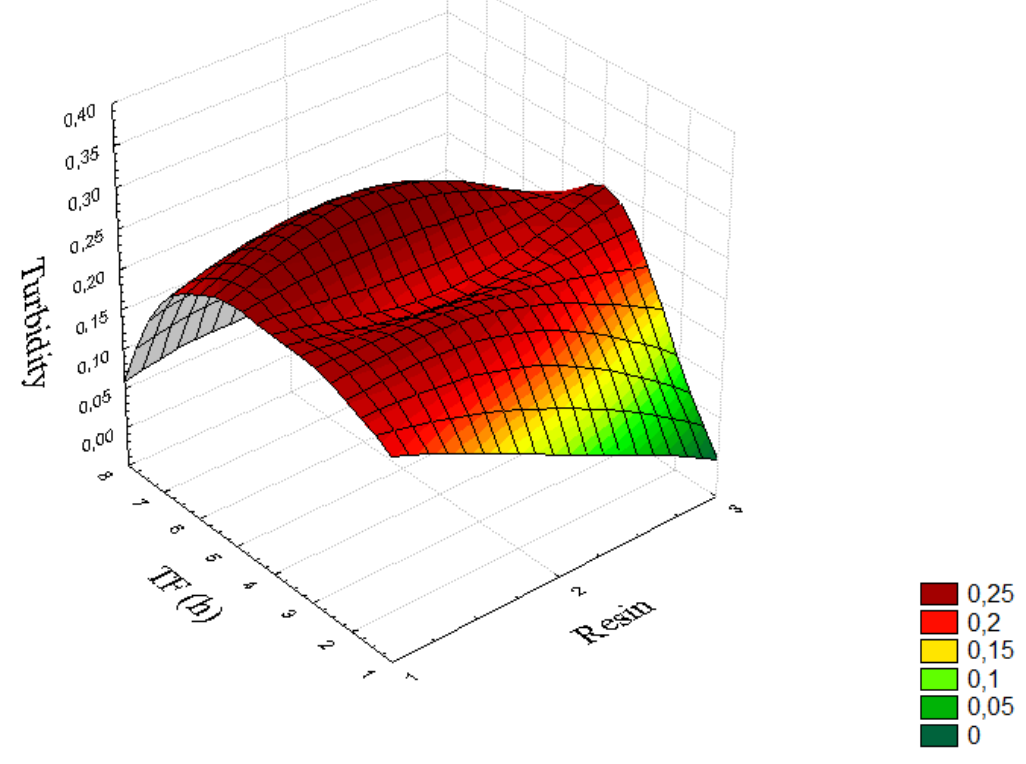

Fig. 3. Response surface for the effect of type of resin and filtration time (FT) on filtrate turbidity. (1- RA; 2-RC; 3- RM)

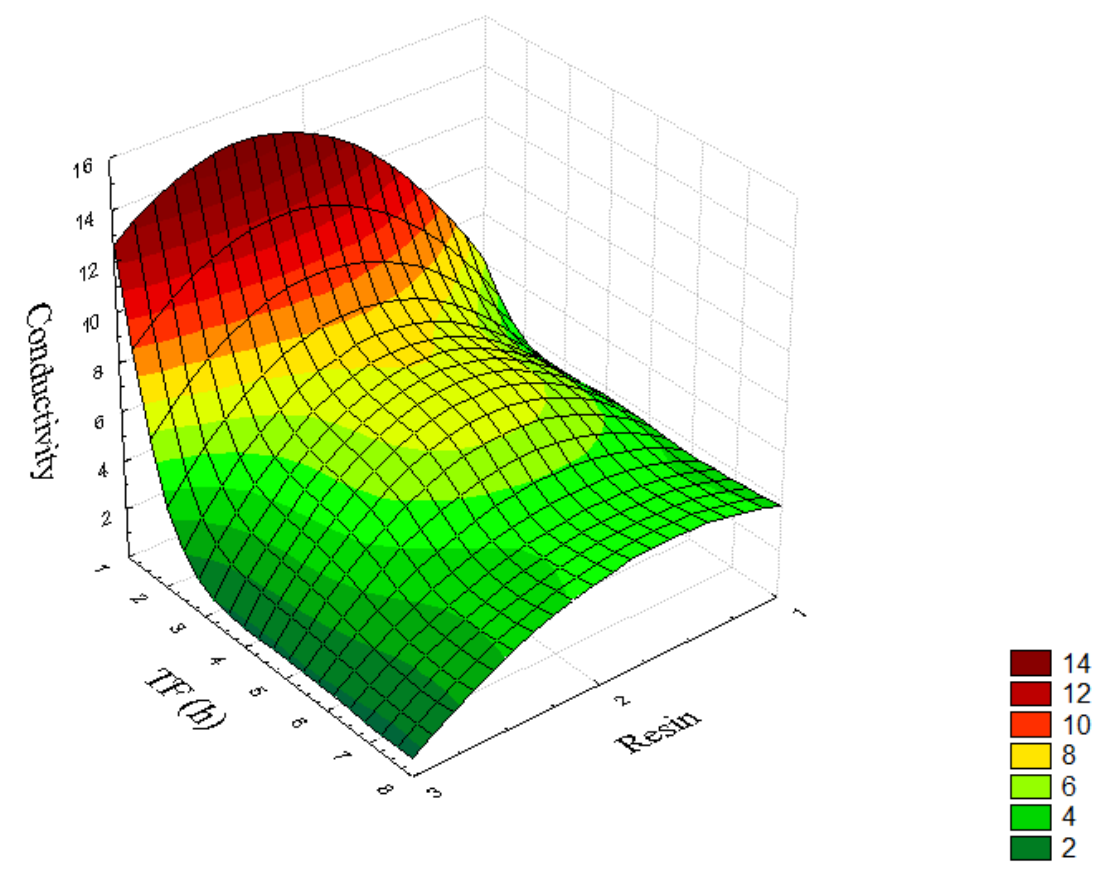

Fig. 4. Response surface for the effect of type of resin and filtration time (FT) on the filtrate conductivity. (1- RA; 2-RC; 3- RM) 
M. R. Franco Júnior et al.: Removal of LAS from water by activated carbon and resins in a continuous process.

\section{CONCLUSIONS}

In this study, adsorption of LAS on three types of resins and four different sizes of activated carbon were investigated. The conventional constant pressure filtration method was used and the LAS initial concentration was maintained by using simple recirculation of the solution. In a single contaminant system, LAS has the highest affinity to the anionic resin and AC with 300 mesh.

Maximum adsorbed mass of LAS was similar comparing anionic and mixed resins. The maximum adsorbed amount (87.2\%) was reached after six hours of filtering.

Acknowledgement: This research was partially supported by the Rio Verde University (Proposal approved in CHAMADA INTERNA 02/2018 PRPI/UniRV-Scholarship of N. A. F. Rocha).

Conflict of interests: The authors declare that there is no conflict of interests regarding the publication of this paper.

\section{REFERENCES}

1. C. L. Yuan, Z. Z. Xu, M. X. Fan, H. Y. Liu, J. Chem. Pharmaceut. Res. 6 (7), 2233 (2014).

2. HERA, Human \& Environmental Risk Assessment on Ingredients of European Household Cleaning Products. Substance: Fluorescent Brightener FWA1 (CAS 16090-02-1), vol 69, 2002.
3. HERA, Linear alkylbenzene sulphonate, available at: http://www.heraproject. com/files/HERA-LAS revised April 2013 Final1.pdf.

4. M. Palmer, H. Hatley, Water Research 147, 60 (2018).

5. A. K. Mungray, P. Kumar, Bioresour. Technol., 99(8), 2919 (2008), https://doi.org/10.1016/ j.biortech.2007.06.025.

6. S. Gonzalez, M. Petrovic, D. Barcel, Chemosphere, 67(2), 335 (2007). https://doi.org/10.1016/ j.chemosphere.2006.09.056.

7. HERA, Human \& Environmental Risk Assessment on Ingredients of European Household Cleaning Products, 2009, p. 1.

8. J. L. Berna, G. Cassani, C.-D. Hager, N. Rehman, L. López, D. Schowanek, J. Steber, K. Taeger, T. Wind, Tenside Surfactant Deterg. 44, 312 (2007). https://doi.org/10.3139/113.100351.

9. M. J. Scott, M. N. Jones, Biochim. Biophys. Acta Biomembr., 1508, 235 (2000). https://doi.org/10. 1016/S0304-4157(00)00013-7.

10. G. G. Ying, Environ. Int., 32, 417 (2006). https://doi.org/10.1016/j.envint.2005.07.004.

11. F. Motteran, B. M. Nadai, J. K. Braga, E L. Silva, M. B. A. Varesche, Science of the Total Environment, 640-641, 1411 (2018).

12. I.-H. Yoona, X. Meng, C. Wang, K.-W. Kim, S. Bang, E. Choe, L. Lippincott, Journal of Hazardous Materials, 164, 87 (2009).

13. Q. Yu, R. Zhang, S. Deng, J. Huang, G. Yu, Water Research, 43, 1150 (2009).

14. Y. Nie, H. Kato, T. Sugo, T. Hojo, X. Tian, Y.-Y. Li, Chemical Engineering Journal, 315, 83 (2017). 